\title{
The Proof is in the Picture: The Influence of Imagery and Experience in Perceptions of Hurricane Messaging 0
}

\author{
LAURA N. RICKARD \\ Department of Communication and Journalism, University of Maine, Orono, Maine \\ JONATHON P. SCHULDT \\ Department of Communication, Cornell University, Ithaca, New York \\ GINA M. EOSCO \\ Eastern Research Group, Arlington, Virginia \\ CLIFFORD W. SCHERER \\ Department of Communication, Cornell University, Ithaca, New York \\ RICARDO A. DAZIANO \\ Department of Civil and Environmental Engineering, Cornell University, Ithaca, New York
}

(Manuscript received 8 April 2016, in final form 23 August 2016)

\begin{abstract}
Although evidence suggests that photographs can enhance persuasive messaging by offering "proof," less research considers their utility relative to other visual forms that ostensibly convey more information but more abstractly. Drawing on communication and information processing theory, this study examines the influence of visual features and personal experience variables in a domain with urgent need to better understand their role: hurricane messaging. In a between subjects experiment, residents of New York, New Jersey, and Connecticut $(N=1052)$ were exposed to a hypothetical hurricane forecast accompanied by a photograph of storm surge inundating a house (indexical image), a map of projected storm surge (iconic image), or no image (control), depending on condition. Results revealed that participants in the indexical condition perceived the greatest risk overall and were more likely to mention evacuation as a behavioral intention than did those in the iconic and control conditions, controlling for individual differences (gender, state of residence, etc.). Moreover, risk perception was greatest among residents in the indexical condition reporting fewer personal impacts of hurricanes, suggesting a moderating effect of hurricane experience on risk judgment but not on behavioral intention. Consistent with a dual-process model perspective, when exposed to an image of an identifiable "victim," participants with less direct experience may have employed an affect heuristic, resulting in heightened risk perceptions. Practically speaking, using evocative photographs as proof may be preferable to a map or text-only approach when warning public audiences of a given hazard, but ethical issues and empirical questions remain.
\end{abstract}

\section{Introduction}

On 29 October 2012, Hurricane Sandy made landfall on the U.S. East Coast, producing storm surge between 3 and $9 \mathrm{ft}$ above ground level and forcing high coastal water

Supplemental information related to this paper is available at the Journals Online website: http://dx.doi.org/10.1175/WCAS-D-16-0048.s1.

Corresponding author e-mail: Laura N. Rickard, laura.rickard@ maine.edu levels from Georgia to Maine. Wreaking particular havoc in the tri-state area of Connecticut (CT), New Jersey (NJ), and New York (NY), the storm cut off electricity to 8.5 million people, impacted more than 650000 coastal homes, damaged public transit systems, and subjected travelers across the nation to delays from flooded runways at La Guardia and Kennedy Airports. All told, Sandy was responsible for over $\$ 50$ billion in damages and claimed 147 lives, despite repeated warnings from officials regarding the magnitude of the impending threat (NOAA 2013). 
The story of Hurricane Sandy is not only about failed infrastructure and inadequate emergency management planning; in large part, it is also a tale of communication challenges (NOAA 2013), in which the features and implementation of warning messages, and the manner in which such messages may be processed by their intended audience, played a critical role. Whether appearing in television news or on government websites, hazard messaging often incorporates two types of visual information: "iconic" representations, such as maps of impact, and "indexical" images, such as photographs of on-the-ground conditions (Messaris 1997). To increase perceived certainty that a predicted weather event will occur, and to bolster audience risk perceptions to a level commensurate with expert forecasts, past research recommends presenting indexical images-photographs of damage, for example-rather than iconic images (Eosco 2014). Yet, to ensure that individuals can take preventive actions (e.g., evacuate their homes) in a timely manner, information must be conveyed before a storm occurs, that is, when photo documentation of the present threat is often unavailable. As a result, iconic images, such as forecast maps that depict anticipated storm trajectory, are often the default choice for those tasked with creating visual representations to accompany hazard messages. In the absence of "proof" afforded by indexical images, however, how do audiences perceive sufficient risk, such that they will undertake appropriate mitigating actions? And how might the audience's past experiences affect their interpretation of this information?

To explore these questions, the present study draws from literature in communication, risk perception, and related fields. Integrating diverse research on the role of imagery in persuasion and attitude change (e.g., Liberman and Trope 2008; Slovic 2007; Zillmann 2002), we extend this work by considering two competing predictions about the role of personal experience in visual persuasion contexts. On one hand, classic dual-process models in persuasion, such as the elaboration likelihood model (Petty Cacioppo and Goldman 1981) and the heuristic-systematic model (e.g., Chaiken 1980), posit that the vivid and emotionally evocative features of indexical visuals may be most impactful among audience members with less personal experience with the depicted hazard, who may lack the motivation or ability to engage in deeper, more systematic processing demanded by iconic visuals. On the other hand, emerging research in risk perception theory suggests that direct (lived) experience with hurricanes is likely to evoke strong cognitive and emotional responses, implying that indexical visuals may be most impactful among individuals with more personal experience with the depicted hazard.

In addition to representing a timely and important topic in its own right, the context of hurricane messaging affords an ideal platform for exploring these alternative predictions about the role of audience experience in the persuasive effects of visuals. We report on a large-scale survey experiment involving residents of $\mathrm{CT}, \mathrm{NJ}$, and $\mathrm{NY}$ who were asked to evaluate hurricane messages that featured either an indexical visual (i.e., a house inundated with storm surge), an iconic visual (i.e., a regional map depicting storm surge projections), or no visual at all. Importantly, respondents completed key measures related to risk perception in addition to reporting on their past hurricane experience. Results shed light on the conditions under which indexical imagery is likely to exert a persuasive effect as a function of audience characteristics, carrying implications for both communication theory and hazard messaging efforts.

\section{Literature review}

\section{a. The role of visuals in science communication}

Scholars have increasingly recognized the power of pictures in communicating scientific information (Rodriguez-Estrada and Davis 2015; Trumbo 1999); as Trumbo (1999, p. 421) argues, "Contemporary science communication relies on visual representation to clarify data, illustrate concepts, and engage a public through an ever-increasing arsenal of computer graphics and new media tools." Just what meaning(s) these images convey, however-in addition to the attitudes and behaviors they may provoke in audiences-is far from straightforward (Burri 2012). Complicating matters, some scientific information, such as a potential cancer diagnosis or an approaching hurricane, represents abstract ideas-possible outcomes that may be (at present) unobservable in a physical sense. These and other health or environmental risks tend also to be uncertain (in occurrence and/or magnitude), and research suggests that some visual attributes, such as use of color or degree of image focus, may affect audiences' perceptions of chance (Severtson 2015; see also MacEachren et al. 2005; MacEachren et al. 2012). Moreover, the verbal (or written) information accompanying visual images also matters, as evidence suggests that individuals combine "redundant" visual and verbal content when interpreting complex verbal-visual messages (Drew and Grimes 1987; Grimes 1990). While the literature considering the role of visuals is diffuse-drawing from such fields as sociology, decision sciences, and semiotics-recent research in communication converges on the persuasive role visuals may play in affecting attitudes, perceptions, and message elaboration, which we explore below.

Visual depictions of scientific information can promote learning (Shah and Miyake 2005; Wogalter 2006) and 
shape perceptions of risk (Bostrom et al. 2008; Chen and Yang 2015; Dixon 2015; Eosco 2014; Lipkus and Hollands 1999). In a review of visual methods employed to communicate about health risks, Lipkus and Hollands (1999) suggest that image design choices can influence how individuals "anchor" the probability and severity of a less-known risk, such as developing cancer from radon exposure, relative to a more familiar reference point, such as smoking cigarettes (see also King 2015). When accompanying text-based messages, visual images can also inform support for (or opposition to) health policy issues, such as the controversial (but scientifically unsubstantiated) link between autism and vaccines (Dixon et al. 2015) or the complex social determinants influencing obesity in the United States (Lundell et al. 2013).

Beyond influencing attitudes and building knowledge, visual images can also play a role in how individuals process information and make behavioral choices. Recent research suggests that certain visuals, such as infographics, can foster message elaboration with respect to environmental issues (Lazard and Atkinson 2015) and bolster (or depress) feelings of self-efficacy surrounding climate change adaptation behaviors (O'Neill et al. 2013; O'Neill and Hulme 2009; O'Neill and Smith 2014; Shaw et al. 2009). Similarly, visuals appearing in informational pamphlets available in healthcare settings can promote willingness to engage in preventive behaviors, such as performing self-examinations to detect melanoma (King et al. 2015).

\section{b. Iconic and indexical images}

While the above review makes clear that visuals have been an active topic of inquiry in science-related contexts, the distinction between iconic and indexical images has received less attention in communication scholarship more generally. In the context of advertising, Messaris (1997) suggests that visual images gain their persuasive power, in part, through the properties of iconicity and indexicality. ${ }^{1}$ An iconic visual representation, such as the National Hurricane Center (NHC)'s recently reformatted storm surge inundation map (see Fig. 2), "characterize[s] some form of similarity or analogy between the sign and its object" (Messaris 1997,

\footnotetext{
${ }^{1}$ Other research in visual learning/literacy and semiotics proposes additional concepts to describe and classify the characteristics of visuals, including the notationality and description/depiction continuums (e.g., Eilam 2012; Goodman 1969; MacEachren and Gantner 1990). For instance, a photograph might be considered more of a depiction of an object, as it highly resembles the object, whereas a map might be thought of as a description, as it stands for a more abstract idea (such as the impacts of an impending storm).
}

p. viii). Specifically, the storm surge map represents the magnitude of projected storm surge using symbolic abstraction-notably, the use of different colors to represent the relative depth of expected surge. In comparison, indexical images, such as photographs or video of the damage from a hurricane, offer relatively concrete "documentary evidence" (Messaris 1997, p. xvi) to audiences. That is, indexical images contain visual features that are "caused by its object and [serve] as a physical trace pointing to its existence" (Messaris 1997, p.viii). Photographs and video thus act as proof that an object exists (Eosco et al. 2012; Messaris 1994, 1997; Sontag 1977). Although both indexical and nonindexical visuals can convey multiple meanings, neither visual "type" can confer causality in the conclusive way that spoken language does, a phenomenon Messaris (1997) refers to as "syntactic indeterminacy.",2 Thus, the viewer's perspective, including her particular experience and personal characteristics, can influence the meaning she attaches to the visual, an idea we return to below.

From a practical standpoint, communicators tasked with providing visual representations of future events are often left to employ iconic visuals; however, indexical depictions of past events (e.g., a photograph depicting damage from a hurricane) can, of course, serve as indexical proof of what is possible and may occur in the future. By definition, indexical proof of an event is unavailable for events that have yet to occur, which encompasses much of the subject matter of risk communication, broadly, and meteorology, specifically (Eosco 2014). In the case of communicating hurricane risk, for example, information about the storm track and intensity must be conveyed several days before a storm makes landfall in a geographic area to ensure that individuals have sufficient time to enact recommended behaviors (e.g., evacuation); however, emerging research on weather hazard messaging suggests that the uncertainty inherent in the iconic visuals that meteorologists provide may undermine their persuasive goals. Eosco (2014) examined real-time response to live television coverage of a tornado event and found that compared to iconic images (i.e., radar of tornado), exposure to indexical images (i.e., video of tornadoes) inspired higher judgments of certainty and perceived risk of tornadoes. By extension, messaging in the hurricane context may similarly produce elevated risk

\footnotetext{
${ }^{2}$ Research by Barbara Tversky and colleagues measuring individuals' mental models in the context of interpreting maps versus textual descriptions of spatial routes may challenge this concept (e.g., Taylor and Tversky 1992).
} 
perceptions in audiences by using photographs that portray hurricane risks, such as flooding induced by storm surge, in a vivid and concrete fashion-a possibility we explore in the present work.

\section{c. Images, heuristics, and information processing}

That exposure to photographs can lead to higher risk judgments (as compared to iconic or nonvisual representation of the risk) is further supported by theories of media influence and social cognition, particularly, exemplification theory and the literature on the identifiable (or identified) victim effect. Exemplification theory (Zillmann 1999, 2002; see also Dixon 2015; King 2015) speaks to the effects that follow from the widespread tendency of media to portray concrete instances of objects or events (i.e., exemplars) as a stand in for the broader category of events at hand. Informed by psychological and evolutionary perspectives on human information processing more generally, exemplification theory posits that such concrete portrayals attract heightened attention, deeper processing, and ultimately increased comprehension and information storage, as compared to more abstract, pallid representations, thus carrying direct consequences for how audiences perceive the focal issue. For instance, studies have demonstrated the persuasive power of portraying a single, identifiable victim-as compared to portraying an anonymous victim or statistics that convey a greater magnitude of victimsto motivate audiences to help those in need (Kogut and Ritov 2005; Slovic 2007; Small et al. 2007). Although the cited research has focused on vivid versus pallid depictions of human victims, it is reasonable to expect similar psychological factors to be involved when people are presented with vivid versus pallid depictions of threats to certain inanimate objects (e.g., a house), which strongly implies a small number of potentially "save-able" victims (see Jenni and Loewenstein 1997).

As others have noted (Zillmann 2002), the representativeness and availability heuristics, in particular, may help account for the persuasive power of exemplars. The representativeness heuristic holds that judgments of the likelihood that a particular instance A (whether a person, object, or event) belongs to a category B is based on the extent to which $\mathrm{A}$ is perceived to approximate (or represent) the prototypical mental image that people hold of B (Tversky and Kahneman 1974). For instance, a student who is highly intelligent and methodical might be assumed to be an engineer, regardless of the actual frequency of engineers in a given population. This so-called base-rate neglect-a violation of Bayes' theorem-reflects the operation of an oftentimes useful cognitive shortcut that can nevertheless perpetuate stereotypes and misinform decisions. Similarly, the availability heuristic (Tversky and Kahneman 1974) posits that individuals assess the likelihood of an event not by its actual frequency but rather by how easily relevant instances can be conjured. Biases emerge in estimating the frequency of events that, while infrequent, attract more attention and are generally easier to recall (e.g., plane crashes versus car crashes). In other cases, lacking exposure to a particular object or event can lead individuals to generate what Tversky and Kahneman (1974) label an "ineffective search set," as when laboratory participants overestimate certain words that can be more quickly brought to mind.

Drawing on research in visual communication and on the depiction of identifiable victims in persuasion, we hypothesize the following:

H1-A message containing an indexical visual of a hurricane impact will exert a stronger effect on risk perception (H1a) and behavioral intention (H1b) as compared to a message containing an iconic visual or no visual at all.

$\mathrm{H} 2$ - A message containing an iconic visual will exert a stronger effect on risk perception $(\mathrm{H} 2 \mathrm{a})$ and behavioral intention $(\mathrm{H} 2 \mathrm{~b})$ as compared to a message containing no visual.

\section{d. Dual-process accounts and the role of experience}

The fundamental role of personal experience and message relevance in persuasion and attitude change has been widely acknowledged for nearly four decades in the communication and social psychological literatures. Prominent dual-process accounts of information processing-notably, the elaboration likelihood model (Petty and Cacioppo 1986) and the heuristic-systematic model (Chaiken 1980)-share a general distinction between two broad systems of reasoning: one characterized by relatively associative, automatic, and low effort processing and one characterized by relatively deliberative, controlled, and high effort processing [for reviews, see Evans (2008) and Kahneman (2013)]. Moreover, both theories make predictions about the conditions under which an individual will engage in less effortful (system 1) versus more effortful (system 2) processing. When it comes to the effectiveness of persuasive messaging, in particular, the individual difference variable of personal relevance has received perhaps more empirical attention than any other, with robust evidence that personal relevance of the topic is positively correlated with deeper or "central" messaging processing and 
less reliance on heuristics (or peripheral cues) in formulating judgments (e.g., Petty et al. 1981).

We expect that the personal relevance of depicted hazards may similarly contribute to the effect of indexical versus iconic images on risk judgments. The depiction of exemplars in indexical visuals (e.g., photographs) is, by definition, more concrete and vivid-qualities that are likely more evocative of the affective responses that are theorized to underlie the heightened persuasiveness of identifiable victims (e.g., Slovic 2007). In contrast, the more abstract and pallid qualities of iconic visuals (e.g., maps) are likely less evocative of such affective responses. Moreover, cognitive psychology research suggests that pictures (relative to words) convey information in more concrete, unique, and contextualized ways (see Amit et al. 2008), that is, psychologically "near" (or proximal) qualities that may further contribute to the heightened persuasiveness of hazard photographs examined here. Although a wide variety of information presentation modes can serve as the basis for peripheral processing (see Lazard and Atkinson 2015), we expected that-from a dual-processing perspective-the concrete and vivid qualities of indexical visual depictions of hazards may serve as the basis for heuristic processing of risk information. If so, we would expect larger effects of such depictions among individuals for whom the focal hazard is less personally relevant and thus would not be expected to engage in more systematic and controlled information processing (Petty et al. 1981).

However, unlike empirical studies within the dualprocess framework that vary personal relevance (or issue involvement) by manipulating whether or not a novel event applies to a given individual (e.g., a policy requiring all graduating seniors to pass a comprehensive exam beginning next year or in 10 years; Petty and Cacioppo 1984), personal relevance in the hurricane context may involve a unique set of emotions and cognitions that should be taken into account. In this vein, recent research suggests that personal relevance in the form of lived experience with severe weather or natural hazards plays an important role in risk information processing, where it has been linked to increased issue salience, risk perceptions, issue understanding, and behavioral intentions (Demuth et al. 2016; Harvatt et al. 2011; Horney et al. 2010; Lazo et al. 2015; Lindell and Perry 2012; Sherman-Morris 2013; Whitmarsh 2008). Generally speaking, such experience tends to increase one's perception of risk associated with that hazard (Trumbo et al. 2011; Peacock et al. 2005). Further, the type of experience, including the severity of the event, whether it was a "false alarm" (e.g., Dow and Cutter 1998; Meyer 2006), or the quality of one's evacuation experience, can shape the extent to which past experience motivates subsequent behavior, such as to evacuate before an impending storm (Lazo et al. 2015; Sharma and Patt 2012). Surveying households adjacent to the U.S. Gulf Coast, Trumbo et al. (2011) showed that having less experience in general, and also less direct experience of Hurricanes Rita and Katrina, predicted lower perceptions of hurricane risk; moreover, those who lived further from the impacts of Hurricanes Rita and Katrina tended to perceive lower risk. Similarly, in communities in England at high risk for flooding and sea level rise, Harvatt et al. (2011) found that lack of personal experience with flooding depressed risk perception as well as motivation to take preventive action (see also Spence et al. 2011).

In sum, whereas dual-process models in persuasion may predict larger effects of indexical visuals among audience members who have had less personal experience with the depicted hazard, emerging research in natural hazard risk suggests that such visuals may be especially impactful among audience members with more personal experience, given that such individuals may experience stronger cognitive and emotional responses when exposed to such vivid reminders of their past experiences. To explore these alternative possibilities, we ask the following:

RQ1-To what extent does an individual's past hurricanerelated experience moderate the effect of indexical versus iconic visual imagery on risk perception and behavioral intention?

\section{Methods and analysis}

\section{a. Data collection}

We analyzed data from respondents recruited through the web panel maintained by Qualtrics (see https://www. qualtrics.com/market-research/panel-management/), who completed an online survey between 15 and 20 April 2015. The present study was limited to residents of Connecticut, New Jersey, or New York State in order to increase the probability that respondents who experienced at least one Atlantic hurricane firsthand were included in the sample. Participants first answered questions concerning their previous experience with hurricanes, such as whether or not they had ever evacuated or experienced property damage. Before presenting these questions, we reminded participants that hurricanes could include both primary impacts (e.g., high winds) and secondary impacts (e.g., loss of electricity). Participants next proceeded to the experimental portion of the questionnaire, which involved reading a hurricane forecast (see below). After reading the forecast, participants answered questions gauging their perceived risk 
related to the impending hurricane, the believability of the forecast, and what actions they might take based on receiving this information. Finally, participants shared whether they had experienced impacts from Hurricane Irene (see below) and reported individual characteristics before being directed to a debriefing page. On average, the survey took just under $10 \mathrm{~min}$ to complete.

\section{b. Experimental conditions}

Participants were randomly assigned to read one of three versions of a forecast about "Hurricane Pat,"3 described as a hypothetical storm, and to answer questions about the storm with respect to where they currently live. Meant to mimic the type of information presented in an online source, such as a weather blog, the message, titled "Hurricane Pat Forecast Update," provided the following: 1) information about the current status of the hurricane, including its location, wind speed, and the issuing of a hurricane watch;2) information about storm surge, including a definition of the term and a projection for the coastal CT, NY, and NJ area; 3) a sentence describing the visual (excluded in the no visual condition); 4) a message about attribution of responsibility for avoiding harm from the hurricane; and 5) a concluding sentence directing readers to check back at 2300 local time for more information on the storm. Word choice and phrasing were varied only minimally across conditions, and word count ranged from 283 words (in the no image, individual responsibility condition) to 364 words (in the map, shared responsibility condition). ${ }^{4}$ Average response time for completing the entire questionnaire did not vary significantly by experimental condition: $F(2,1049)=0.15$, and $p=0.86$.

To manipulate visual type, we presented participants in the experimental groups with either an indexical image (i.e., a photograph) or an iconic image (i.e., a map). The photograph portrayed a single-family house being inundated by storm surge and was chosen, in part, for validity purposes, given that it had appeared in prior media coverage (e.g., Denver Post) of U.S. East Coast hurricane damage (Fig. 1). The map was an actual storm surge inundation map created by the NHC that depicted storm surge levels (in feet) in parts of New York (including Brooklyn, Manhattan, and Staten Island) and

\footnotetext{
${ }^{3}$ Given recent attention to the possible influence of hurricane name gender on perception of the event (Jung et al.2014), we chose the name Pat as representative of a gender neutral name (i.e., could be attributed to a man or woman).

${ }^{4}$ The design also explored an additional variable, attribution of responsibility for avoiding hurricane harm (as an individual or shared responsibility), which showed no effects on our dependent variables $(|t|<1.25$, ns). Therefore, we collapsed data across this variable for analysis purposes.
}

New Jersey (Fig. 2). ${ }^{5}$ Although the map symbolized a far greater extent of damage than the photograph, it nevertheless depicted a narrower geographic region compared to that from which our participants were drawn. For this reason, we control for participant location (e.g., CT vs NY or NJ) in the present analyses. ${ }^{6}$

\section{c. Measurement}

\section{1) RISK PERCEPTION}

Risk perception consisted of two sets of measures: 1) the perceived likelihood that Hurricane Pat will harm the coastline from (i) wind, (ii) storm surge, or (iii) secondary impacts (e.g., lack of public transit; 6-point scales ranging from $1=$ very unlikely to $6=$ very likely), and 2) the perceived severity of the threat posed by (i) wind, (ii) storm surge, and (iii) secondary impacts (5-point scales ranging from $1=$ not at all serious to $5=$ very serious; Zhao et al. 2011). Correlations between these six items were all positive ( $r$ range $=0.33-0.75)$. For each of the three categories (i.e., wind, storm surge, and secondary impacts), product terms were created based on the two dimensions, that is, likelihood $\times$ severity, following past research (Zhao et al. 2011). Subsequently, we averaged the three terms into an index to assess risk perception, resulting in a possible score range of 1-30 (Table 1).

\section{2) HurricANE-RELATED EXPERIENCE}

Past research on experience of weather and natural hazards often employ summative variables that can include both direct (i.e., with respect to the individual) and indirect (i.e., with respect to close others, such as family and friends) experience (e.g., Lindell and Hwang 2008; Trumbo et al. 2011). In the following, we used six items, adapted from Trumbo et al. (2011), that asked specifically about direct and indirect experiences related to hurricanes (e.g., has your home experienced any storm surge from a hurricane? yes, no, do not know/cannot remember).

Subsequently, we summed the number of yes responses across the six items to create an additive scale of overall experience of hurricane impacts (range 0-6).

\footnotetext{
${ }^{5}$ Because we expected participants' hurricane-related recall to be primarily based on Hurricane Sandy, we elected to avoid any explicit mention to Sandy in the experimental stimuli. (The photograph was described as depicting Hurricane Irene, and the map was described as depicting the hypothetical Hurricane Pat).

${ }^{6}$ Although the residences of some of our participants (notably, Connecticut residents) were not represented on the stimulus map, follow-up analyses suggested that this played no role in the present findings. Specifically, no interaction effect between experimental treatment and participant location (CT, NY, or NJ) was observed on either our risk judgment or behavioral intention measure $(p>0.60)$.
} 


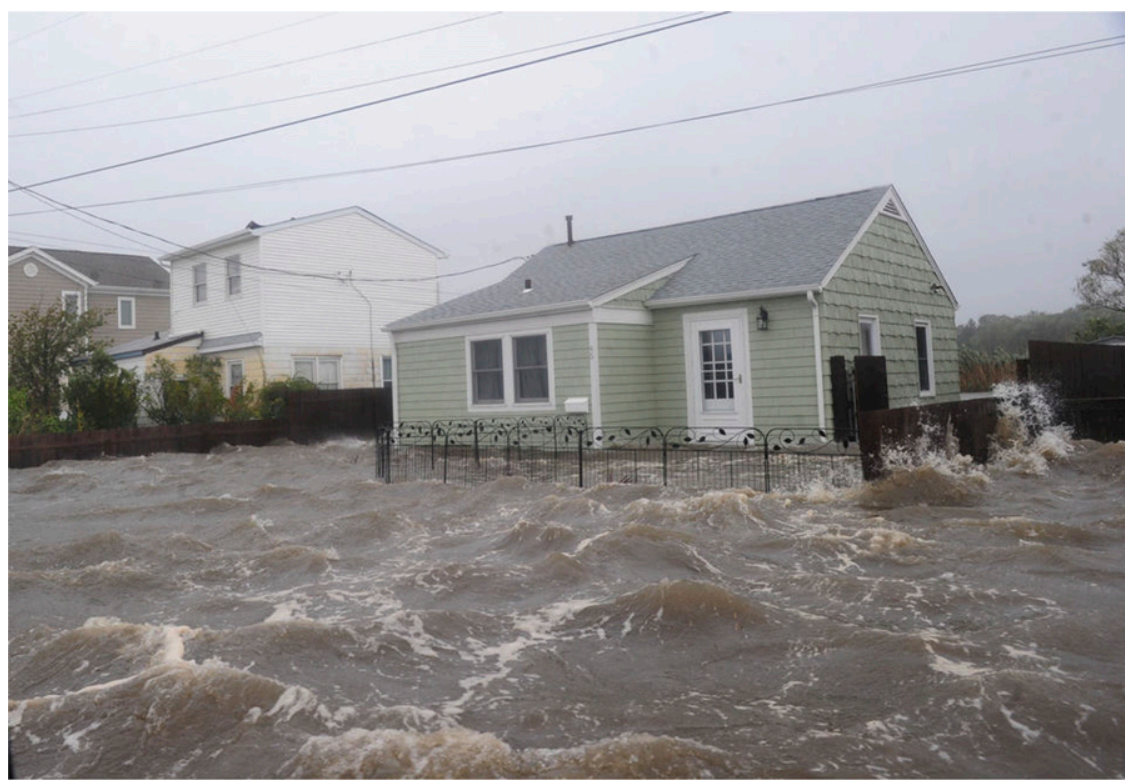

FIG. 1. Photograph depicting storm surge damage from Hurricane Irene in August 2011 (also used in the photograph experimental condition).

\section{3) BEHAVIORAL INTENTION}

We measured behavioral intention with a freeresponse item that asked: "Based on what you have read about hypothetical Hurricane Pat, what do you think you would do at this point?" Responses that mentioned evacuation were coded as 1 , including planning to evacuate, waiting for evacuation orders, or referring to evacuation with alternative language (e.g., I would leave town); those that that did not mention evacuation were coded as 0 . Two independent coders categorized the open-ended responses as mentioning evacuation-related intentions or not, achieving a high level of reliability $(r=$ 0.93 , based on a subset of 100 cases).

\section{Results}

\section{a. Study sample}

The sample $(N=1052)^{7}$ was predominately female (63.5\%; 668 females, 383 males, 1 missing), White/ Caucasian (77.3\%) (813 White, 93 African American,

\footnotetext{
${ }^{7}$ There were $N=2048$ respondents that initially responded to the survey, but $51 \%$ completed the full questionnaire in a satisfactory manner, resulting in a final analytic sample of $N=1052$. More specifically, Qualtrics excluded respondents meeting one or more of the following criteria: 1) Incorrect responses to one or both attention questions meant to filter out inattentive survey takers; 2) resided in a state other than $\mathrm{CT}, \mathrm{NY}$, or $\mathrm{NJ}$; or 3 ) failed to agree to the terms of informed consent outlined at the beginning of the questionnaire.
}

103 Asian, 43 other/multiracial), and 42 years old, on average $(M=41.88, \mathrm{SD}=19.59)$. The sample was also fairly educated, with a majority $(58.8 \%)$ reporting that they held at least a college degree. Other measured items included personal characteristics often associated with hurricane-related risk perceptions and decisionmaking, including living arrangement (62\% homeowners), relationship status (47\% married), disability status (11\% reported own disability or of someone s/he cared for), number of children in household (18\% had at least one child living at home), and primary language spoken at home (96\% English).

\section{b. Preliminary analyses}

First, to check that our randomization to condition was effective, we tested for any differences among the three treatment conditions in individual characteristics (age, gender, education, state, etc.). Indeed, no such differences were revealed (all $p>0.50$ ). Importantly, we also checked whether ratings of perceived believability of the hypothetical forecast differed across conditions, which was indeed not the case $[F(2,1043)=1.63, n s]$. Next, because our sample included residents of Connecticut, New York, and New Jersey-individuals who, conceivably, might have varying levels of experience and/or risk perceptions related to hurricanes independent of the experimental manipulation - we examined differences in study variables by state. Results indicated that risk judgment did not differ by state $[F(2,1031)=1.69, p=0.19]$ nor did 


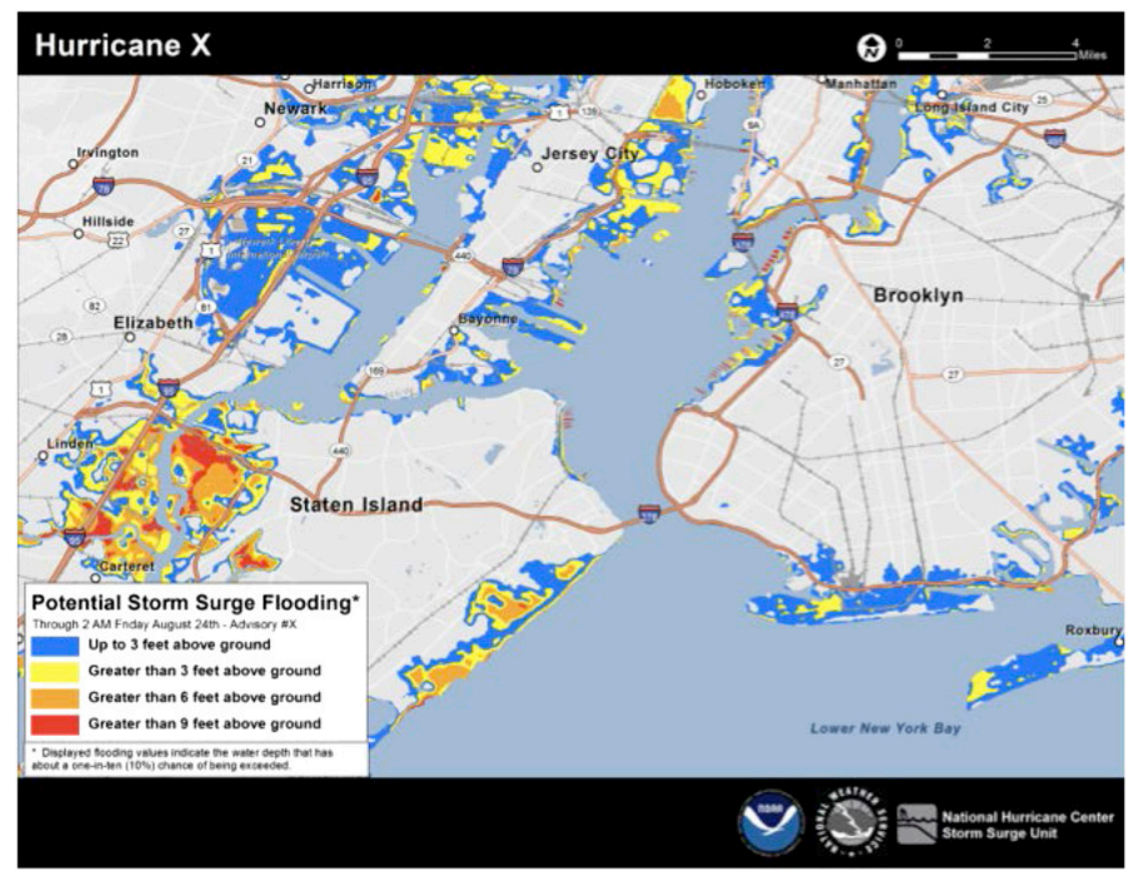

FIG. 2. Sample NHC storm surge inundation map (also used in the map experimental condition).

behavioral intention $\left[\chi^{2}(2)=0.78, p=0.68\right]$ or perceived believability $[F(2,1042)=0.10, p=0.90]$. Experience of hurricane impacts, however, did vary $[F(2,907)=$ $12.89, p=0.000]$, with the highest mean impacts reported by residents of New Jersey $(M=2.83, \mathrm{SD}=1.89)$, followed by New York $(M=2.12, \mathrm{SD}=1.98)$, and Connecticut $(M=2.11, \mathrm{SD}=1.91)$. A post hoc analysis employing a Bonferroni correction showed significant differences between CT and NJ residents and between NY and $\mathrm{NJ}$ residents (all $p<0.05$ ) but not between $\mathrm{CT}$ and NY residents.

\section{c. Role of individual difference variables}

We analyzed the association between our dependent variables (risk perception and behavioral intention) and key individual difference variables (age, gender, education, home ownership status, and race/ethnicity) in light of past research highlighting their importance (e.g., Flynn et al. 1994). Risk perception was positively associated with age $(r=0.12$, $p<0.001)$; females expressed marginally greater risk judgment $(M=19.99, S D=6.13)$ than $\operatorname{did}$ males $(M=$ 19.31, $\mathrm{SD}=6.21 ; F=1.70, p=0.09)$; education showed a weak negative relationship with risk judgment $(r=-0.05, p=0.09)$; homeowners expressed significantly greater risk judgment $(M=20.06, \mathrm{SD}=$ 6.23) than did nonhomeowners $(M=19.24$, $\mathrm{SD}=$ $6.04)$; and race/ethnicity emerged as a significant predictor $[F(5,1029)=2.78, p=0.02]$, with African
Americans reporting the highest risk judgments $(M=$ 20.52, $\mathrm{SD}=6.13$ ) and Asians reporting the lowest risk judgments $(M=17.90, \mathrm{SD}=6.17 ; M=19.97, \mathrm{SD}=6.10$ for the largest group, White). Turning to behavioral intention, the likelihood of expressing evacuation-related intentions was negatively related to age (Spearman's rho $=-0.08, p<0.01$ ), did not vary across females and males [ $30.9 \%$ versus $34.1 \%, X^{2}(990)=0.30$, ns] , was unrelated to education (Spearman's rho $=-0.04, p=$ $0.19)$, was lower among homeowners $(29.4 \%)$ than nonhomeowners $\left[36.1 \% ; X^{2}(992)=4.96, p=0.03\right],{ }^{8}$ and did not vary by race/ethnicity $\left[X^{2}(992)=8.06, p=0.13\right]$.

\section{d. Effects of visual condition}

We expected greater risk perception with respect to Hurricane Pat in the photograph condition as compared to the other conditions (H1a). This hypothesis was supported. Specifically, the overall effect of condition on risk perception was significant $[F(2,1032)=3.04, p<0.05]$, and a follow-up planned contrast revealed that risk perceptions provided by respondents in the photograph condition $(M=20.40, \mathrm{SD}=6.30)$ were significantly

\footnotetext{
${ }^{8}$ Although it may appear contrary to expectation that homeowners expressed higher risk judgments but lower evacuation intentions, we expect that this pattern may reflect, in part, the different levels of control and financial investment that homeowners versus nonhomeowners (e.g., renters) are likely to feel when faced with the prospect of damage to their dwelling.
} 
TABLE 1. Descriptive data for key variables $(N=1052)$.

\begin{tabular}{|c|c|c|c|}
\hline Concept & Measures & $M$ & SD \\
\hline \multirow{7}{*}{$\begin{array}{l}\text { Hurricane } \\
\text { experience }(0=\text { no; } \\
1=\text { yes }^{\mathrm{a}}\end{array}$} & Has your home experienced any storm surge from a hurricane? & 0.26 & 0.44 \\
\hline & Has someone you know experienced any personal loss from a hurricane? & 0.61 & 0.49 \\
\hline & $\begin{array}{l}\text { Has there been an evacuation order for your area from a } \\
\text { hurricane? }\end{array}$ & 0.27 & 0.44 \\
\hline & $\begin{array}{l}\text { Has your neighborhood experienced any storm surge from a } \\
\text { hurricane? }\end{array}$ & 0.40 & 0.49 \\
\hline & $\begin{array}{l}\text { Has your community (e.g., town, city) experienced any storm } \\
\text { surge from a hurricane? }\end{array}$ & 0.53 & 0.49 \\
\hline & Have you experienced any personal loss from a hurricane? & 0.24 & 0.43 \\
\hline & Summed scale & 2.33 & 1.98 \\
\hline \multirow{11}{*}{$\begin{array}{l}\text { Risk perception } \\
\text { (likelihood } \times \\
\text { severity) }\end{array}$} & Perceived severity $(1-5$ scale $)$ : & & \\
\hline & $\begin{array}{l}\text { Based on what you know about the hypothetical Hurricane Pat, how serious do you think } \\
\text { the threat is from: }\end{array}$ & & \\
\hline & Storm surge & 3.67 & 1.07 \\
\hline & Wind & 3.99 & 0.91 \\
\hline & Secondary impacts, such as loss of power, lack of public transit, and so on & 4.08 & 0.86 \\
\hline & Perceived likelihood (susceptibility) (1-6 scale): & & \\
\hline & $\begin{array}{l}\text { Based on what you know about the hypothetical Hurricane Pat, how likely } \\
\text { is it that Pat will harm: }\end{array}$ & & \\
\hline & The coastline from storm surge & 5.08 & 0.95 \\
\hline & The coastline from wind & 4.94 & 0.96 \\
\hline & The coastline from secondary impacts & 4.84 & 0.94 \\
\hline & Calculated scale & 19.74 & 6.16 \\
\hline
\end{tabular}

${ }^{a}$ Do not know/cannot remember responses were excluded from analysis.

greater than those provided by respondents in the map condition $(M=19.49, \mathrm{SD}=6.22 ; p=0.02$ for the contrast; $d=0.15$ ) and the no visual (control) condition $[M=19.34, \mathrm{SD}=5.92 ; F(1,1032)=5.97, p=0.02$; $p=0.05$ for the contrast; $d=0.17]^{9}$; however, risk perceptions did not differ between the map and control conditions $(F<1, \mathrm{~ns})$, and thus we did not find support for $\mathrm{H} 2 \mathrm{a}$.

Analysis of the free-response measure of behavioral intention complemented the effects observed on risk perception. Logistic regression models in which the binary evacuation intention variable $(0=$ did not mention evacuation, 1 = did mention evacuation) was regressed onto condition (composed of two dummycoded variables) revealed significant effects of our visual manipulation. Specifically, relative to both the control (no visual; $B=0.68$, Wald $=17.07, p<0.001$ ) and the map condition $(B=0.84$, Wald $=24.51, p<$ $0.001)$, participants exposed to the photograph were significantly more likely to reference an intention to evacuate in their free response. In percentage terms, whereas $43.1 \%$ of participants who saw the hurricane

\footnotetext{
${ }^{9}$ Although these effects on risk perception would be classified as small in magnitude (Cohen 1988), they may nevertheless be practically substantial if they generalize to real-world risk communication settings.
}

forecast accompanied by the photograph made reference to evacuating, substantially lower percentages who saw the map or no image did the same $(23.9 \%$ and $27.2 \%$, respectively). Thus, the behavioral intention measure offers support for $\mathrm{H} 1 \mathrm{~b}$ but not $\mathrm{H} 2 \mathrm{~b}$. Moreover, these results remained when controlling for key covariates, namely, age, gender, state of residence, education, and race/ethnicity, none of which emerged as a significant predictor in the regression models $(|B|<0.20$, ns $)$.

\section{e. Moderating role of hurricane-related experience}

On the basis of dual-process models and emerging work demonstrating that experience with environmental hazards predicts individuals' risk-related judgments and behaviors, we also explored the role of respondents' reported level of personal experience with hurricanes in this effect (RQ1). First, an ANOVA model featuring condition, hurricane-related experience, and their interaction term revealed a significant interaction effect on risk perception: $F(2891)=4.62$, and $p=0.01$. Follow-up regression analyses were then conducted to diagnose the nature of this interaction effect, which revealed that whereas the photograph condition engendered significantly greater risk judgment $(M=20.61)$ than the map $(M=19.05)$ and control conditions $(M=18.44)$ among respondents reporting relatively low levels of direct hurricane experience (i.e., at 


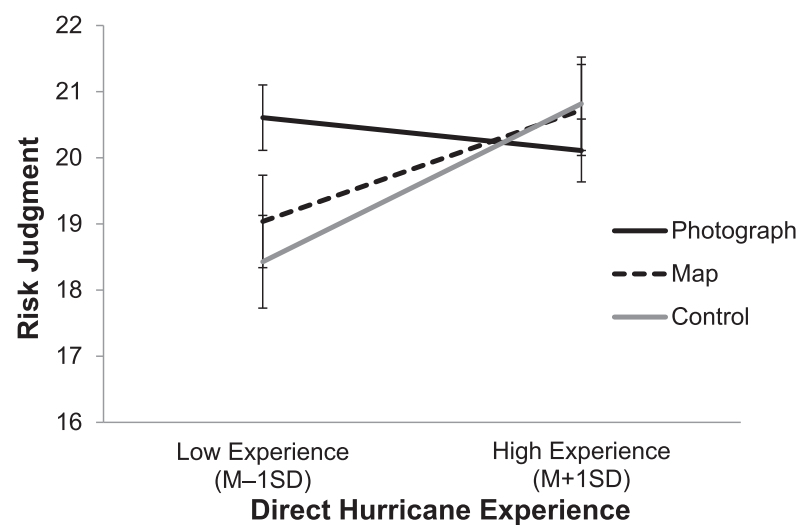

FIG. 3. Graph depicting the effect of experimental condition (photograph, map, and control) on risk judgment by direct hurricane experience (error bars represent mean standard error).

$M-1 \mathrm{SD} ;|t|>2.25, p<0.05),{ }^{10}$ no significant effect of condition was observed among respondents with relatively high levels of direct experience (i.e., at $M+1 \mathrm{SD}$; $M_{\text {photo }}=20.11$ vs $M_{\text {map }}=20.82$ vs $M_{\text {control }}=20.73 ; t \leq 1$, ns; see Fig. 3). This interaction effect remained when gender, education, and state of residence $(\mathrm{CT}, \mathrm{NJ}$, or $\mathrm{NY})$ were controlled as covariates in the model. ${ }^{11}$ In contrast to this moderation pattern observed for risk perception, however, hurricane-related experience did not moderate the effect of experimental condition on behavioral intention $(|B|<0.07$, Wald $<1$, ns). Importantly, the reported effects of visual treatment on risk judgment and behavioral intention remain significant when controlling for all individual difference variables.

\section{Discussion}

Using the real-life context of hurricane messaging, the present study explored the extent to which presenting varying visual information influences how individuals perceive related risk. Results indicate support for our first hypothesis, in that the photo condition engendered the highest risk perception and evacuation behavioral intention, above the map and no visual conditions. These findings were in line with previous work on perceptions of severe weather images (Eosco 2014). When communicating about hurricane risk, visual messages

\footnotetext{
${ }^{10}$ Risk perception at $M-1 \mathrm{SD}$ did not differ between the map and control conditions $(t<1, \mathrm{~ns})$.

${ }^{11}$ Gender, education, and race/ethnicity emerged as significant predictors in this model $(F>4.1, p<0.05)$. Zero-order correlation coefficients revealed that risk perceptions tended to be greater among females $(r=0.06, p=0.07)$, the less educated $(r=-0.05$, $p=0.09)$, and participants identifying as White $(r=0.07, p=0.04)$.
}

employing a single, vivid, indexical exemplar (i.e., a photograph) may be more persuasive than nonvisual messages or messages with iconic visuals; importantly, however, we also found some evidence that this effect may be contingent on the personal characteristics of the respondents. That is, results revealed that the effect of indexical versus iconic imagery on risk judgments was most pronounced among respondents who reported less experience with past hurricanes; in contrast, the effect on behavioral intention to evacuate was observed regardless of level of hurricane experience. In the following discussion, we explore the implications of these findings for communication theory (particularly with respect to visuals and hazard messaging), suggest practical applications, and point to areas for further research.

\section{a. Theoretical implications}

That hurricane experience moderates risk perception provides some evidence of a mechanism by which individuals process indexical and iconic risk images. To further explain this mechanism, we return to the theoretical perspectives explored previously: the role of visual exemplars, dual-process models, and heuristics in judgment. Although the map condition displayed a greater magnitude of potential risk than the photograph condition, that is, the projected risk of storm surge to residents of a multistate region versus the risk to a single house, the house may appear as a clearer "victim" than the diffuse, affected municipalities. While past research has emphasized the effects of a human exemplar, such as an impoverished child, on intentions to act (e.g., Slovic 2007), our research suggests the possibility that the image of an identifiable, threatened home can elicit similar cognitions. Thus, the photo of the single, inundated house may have-for some individuals-inspired deeper processing of the text forecast and, in turn, heightened perception of hurricane risk. Specifically, participants with less direct experience with the hazard may have been especially inclined to employ an affect heuristic when formulating their risk judgments, consistent with a dual-process model perspective. At the same time, however, the effect of visual treatment on evacuation-related behavioral intention was not found to differ by personal experience-a pattern that may reflect the different component factors that underlie behavioral intentions versus risk perception (e.g., perceived subjective norms; Ajzen 1991). Future work may wish to further more directly explore the processes underlying the present effects with additional affect and visual informationprocessing measures (see below).

From the perspective of judgmental decision-making, for those without hurricane experience, an evocative photograph may trigger the availability heuristic 
(Tversky and Kahneman 1974), making the risk of storm surge, for example, a more accessible idea. Rather than an abstract, meteorological term, storm surge instead becomes more concrete and imaginable: waves of muddy water swamping a modest, suburban home. Applying the language of construal level theory (Trope and Liberman 2010), the photograph may evoke, for less-experienced individuals, a low-level construal that is more contextualized and psychologically "close" than the iconic image (i.e., storm surge inundation map). For those who have lived through past hurricanes, however, the accumulated experience of suffering the impacts of these storms may render a single, indexical image less effective at swaying previously formed attitudes. In other words, experience may inform risk perception (and conceivably, related decision-making) for experienced individuals more so than a visual exemplar. To explore these possible explanations, future research would benefit from a more fine-grained measure of hurricane experience (see Demuth et al. 2016), possibly using qualitative methods such as focus groups to uncover the way(s) in which experienced individuals rely on past history to make behavioral decisions, specifically, in the presence of emerging visual information.

\section{b. Practical implications}

Just as research in science communication has emphasized the need to understand audience characteristics to frame messages accordingly (e.g., Maibach et al. 2008; Nisbet 2009), the present research suggests that influencing attitudes in intended ways requires the careful, strategic selection of images with audience traits in mind (Rodriguez-Estrada and Davis 2015). When the goal of the message is increasing perception of risk-a desirable outcome in instances where preventive behavior is time sensitive (e.g., Lindell and Perry 2012)_our results indicate that, in some cases, using an evocative photograph as proof of a given risk may be preferable to a map or text-only approach. Moreover, while this form of communication may be particularly impactful for those without past experience of the risk, we see no evidence of detrimental impacts (e.g., decreased risk perceptions) on those who have lived through similar events. In practical terms, however, providing photographic proof may mean presenting images of past storms to communicate about present (or impending) storms, which may pose ethical implications for risk communicators. Beyond the issues related to truthful attribution of the image, publicizing images from a previous storm, while motivational for some audiences, could also conjure distressing feelings or memories. Moreover, further empirical study is necessary to better understand how risk perceptions and behavioral intentions may vary depending on image attribution, such as whether a photograph is explicitly labeled as depicting a past storm versus an ongoing storm or not attributed to any particular event.

As the National Hurricane Center continues to devote considerable resources to developing new data-driven visual products, such as the storm surge inundation map (NHC 2012; NOAA 2010), to communicate weather risks to public audiences, testing the type and magnitude of impacts of these products with U.S. residents is critical. Interestingly, the present study found no difference in risk perception between the text-only (control) and map conditions; however, the two conditions may have differed on other outcome variables not measured in this research but possibly important to communicating about weather events, such as message recall, perceived selfefficacy, or intention to seek additional information (e.g., Lindell and Perry 2012). Future research should also further examine the extent to which certain images may inspire unintended consequences among certain audiences, including boomerang effects triggered by fear control or reactance (e.g., Hart 2014; Hart and Nisbet 2012).

\section{c. Limitations and future directions}

Two aspects of this research contributed positively to its ecological validity or ability to approximate real-world conditions (Brewer 2000). First, we used a sample of tristate residents who are most likely to have knowledge about and be affected by Atlantic hurricanes. Second, the stimulus presented in the map condition was a mock-up of the actual format used by the National Hurricane Center to represent storm surge inundation levels and thus approximates visual hazard messaging likely viewed by participants in the event of a hurricane (NHC 2012; NOAA 2010). Yet, despite these strengths, this study is not without limitations. While the map stimulus mimicked images used by NHC, the particular image we employed contained only a limited area of NJ and NY; some of our participants lived outside of the region represented by the map, thus potentially influencing perceptions of risk. Related to this, idiosyncratic features of any given indexical image (here, one depicting a particular, single-family house being inundated by water) may limit the generalizability of the present results (Shapiro 2002). Our results might have been different, for example, had the photograph included humans or the map included more red-colored areas than blue. Finally, our experimental conditions differed on other dimensionssuch as the scale of the image (e.g., one house versus a multistate region) and the word count of the associated text-that may have influenced results. Thus, future research involving stimulus sampling (Wells and Windschitl 1999) may be particularly valuable in this domain, and for 
ensuring the generalizability of the results (Jackson 1992), as would be testing for differences invoked by particular word choice in the narratives or the relative "ease of processing" of a given image.

Recent work suggests that negative affect-a variable that we did not measure directly-may mediate the relationship between exposure to a visual exemplar and resulting risk perception (Dixon 2015). Similarly, research finding that risk perception mediates hurricane experience and behavioral intentions has employed nuanced approaches to measuring both experience, such as distinguishing between tangible (e.g., property loss) and intangible impacts (e.g., emotional toll), and risk perception (Demuth et al. 2016). At least three additional individual characteristic variables, not included in our study, may have also helped better explain our findings, including political orientation, often a moderating variable in studies of environmental issues of U.S. audiences (e.g., McCright and Dunlap 2011; Schuldt et al. 2011), as well as dispositional optimism and socioeconomic status, which have been shown to influence hurricane-related risk perceptions (Trumbo et al. 2011). Finally, we chose not to mention Hurricane Sandy as part of this study in part to avoid biasing the relationship between participants' experiences with this salient event and their responses to the stimuli; in so doing, however, we were unable to capture experiences related to this important event, including whether or not participants evacuated or their perception of a "near miss," possibly the case for our upstate New York respondents, who experienced limited effects of Sandy but, in some cases, significant impacts from the earlier Hurricane Irene.

Moving forward, we posit two novel directions for future research. First, in addition to the important role of lived experience, how individuals interpret a given visual also depends, in part, on experience in relation to interpreting the visual-what can be referred to as visual literacy. The concept of visual literacy posits that each individual's competencies, experiences in a given environment, education, and culture, influence interpretation of a given visual as well as related behavioral decisions (Avgerinou and Ericson 1997; Trumbo 1999). On one hand, "reading" a photograph of storm surge impacting a house requires only the innate "skill" of vision and not other, more technical or scientific competencies (see Cassidy and Knowlton 1983; Hochberg and Brooks 1962; Messaris 1994). On the other hand, reading a map of storm surge inundation arguably requires more skill and preexisting knowledge to arrive at its intended meaning, including how to interpret a map legend and the ability to locate one's home (i.e., map literacy). Moreover, a meteorologist viewing the storm surge inundation map may have the "objective experience" as Paivio (2007) describes that affords seeing more proof in the picture than would a nonexpert viewer. If, through their professional training and experience, meteorologists share a "socially organized way of seeing" (Goodwin 1994, p. 606), how do their perceptions of these images compare to those of nonexpert audiences? When thought of as a learned skill (e.g., Perini 2012), rather than simply an innate characteristic, does visual literacy serve as an additional moderator or mediator of processing hazard messages (see Lazard and Atkinson 2015)?

Second, we propose further research to examine the effects of science visuals within the context of a complex media environment. In the span of a limited television forecast, for example, broadcast meteorologists present many visuals to convey the varied risks associated with hurricane events; the storm surge inundation map may represent only $30 \mathrm{~s}$ of a typical 3-min forecast. In addition to covering multiple risk issues and displaying various images, television weather broadcasts also feature accompanying verbal messaging, which may strengthen-or, in other cases, contradict-the visual images displayed (Drew and Grimes 1987; Grimes 1990). Given the (potentially) competing visual and auditory information provided in one forecast, (how) do individuals perceive the risk that is most relevant to them for making behavioral decisions, such as to evacuate an area? Which visuals are perceived as most "informative" in terms of decision-making and why? ${ }^{12}$ Given the brevity of most forecasts, do individuals have sufficient time to process the information, assess their personal risk, and make related behavioral decisions? How do design choices influence ease of processing and "effectiveness" of visual information (Rodriguez-Estrada and Davis 2015)? To answer these and other questions, future research must investigate the possibly dynamic nature of risk perceptions, which may change over the course of a given audiovisual hazard message and/or be influenced by accompanying messages (Eosco 2014). Further, weather broadcasters tend to be influential purveyors of science information, and perceptions of these individuals - whether trusted authority or fallible hackmight mediate or moderate the way(s) in which audiences interpret hazard messaging (Bloodhart et al. 2015; Maibach et al. 2011).

\footnotetext{
${ }^{12}$ In the context of health communication, the emerging concept of perceived visual informativeness (PVI) is one example of a tool to assess the quality of visual (statistical or indexical) information presented across information sources in a systematic manner (King Jensen Davis and Carcioppolo 2014).
} 
Acknowledgments. This manuscript was prepared by the authors using Federal funds from two projects (\#R/CSAP-4-NY and \#R/CSAP-5-NY) funded under the Coastal Storm Awareness Program (NOAA Awards NA13OAR4830227, NA13OAR4830228, and NA13OAR4830229) from the National Sea Grant College Program, National Oceanic and Atmospheric Administration, U.S. Department of Commerce. The federal funds were provided via appropriations under the $\mathrm{Di}$ saster Relief Appropriations Act of 2013 (P.L. 113-2) and the Sea Grant Act (33 U.S.C. 1121 et seq.). Funding was awarded to the financial hosts of the Sea Grant College Programs in Connecticut, New Jersey, and New York via their financial host institutions, the University of Connecticut, the New Jersey Sea Grant Consortium, and the Research Foundation of State University of New York, respectively. The statements, findings, conclusions, and recommendations are those of the author(s) and do not necessarily reflect the views of the National Sea Grant College Program, National Oceanic and Atmospheric Administration, the U.S. Department of Commerce nor any of the other listed organizations.

\section{REFERENCES}

Ajzen, I., 1991: The theory of planned behavior. Organ. Behav. Hum. Decis. Processes, 50, 179-211, doi:10.1016/0749-5978(91)90020-T.

Amit, E., D. Algom, Y. Trope, and N. Liberman, 2008: 'Thou shalt not make unto thee any graven image': The distancedependence of representation. The Handbook of Imagination and Mental Stimulation, K. D. Markman, W. M. P. Klein, and J. A. Suhr, Eds., Psychology Press, 53-68.

Avgerinou, M., and J. Ericson, 1997: A review of the concept of visual literacy. Br. J. Educ. Technol., 28, 280-291, doi:10.1111/ 1467-8535.00035.

Bloodhart, B., E. Maibach, T. Myers, and X. Zhao, 2015: Local climate experts: The influence of local TV weather information on climate change perceptions. PLoS One, $\mathbf{1 0}$ e0141526, doi:10.1371/journal.pone.0141526.

Bostrom, A., L. Anselin, and J. Farris, 2008: Visualizing seismic risk and uncertainty: A review of related research. Ann. N. Y. Acad. Sci., 1128, 29-40, doi:10.1196/annals.1399.005.

Brewer, M., 2000: Research design and issues of validity. Handbook of Research Methods in Social and Personality Psychology, H. Reis and C. Judd, Eds., Cambridge University Press, 3-16.

Burri, R. V., 2012: Visual rationalities: Towards a sociology of images. Curr. Sociol., 60, 45-60, doi:10.1177/0011392111426647.

Cassidy, M., and J. Knowlton, 1983: Visual literacy: A failed metaphor? Educ. Technol. Res. Dev., 31, 67-90, doi:10.1007/ BF02766724.

Chaiken, S., 1980: Heuristic versus systematic information processing and the use of source versus message cues in persuasion. J. Pers. Soc. Psychol., 39, 752-766, doi:10.1037/0022-3514.39.5.752.

Chen, Y., and Z. J. Yang, 2015: Message formats, numeracy, risk perceptions of alcohol- attributable cancer, and intentions for binge drinking among college students. J. Drug Educ., 45, 37-55, doi:10.1177/0047237915604062.
Cohen, J., 1988: Statistical Power Analysis for the Behavioral Sciences. 2nd ed. Erlbaum, 567 pp.

Demuth, J. L., R. E. Morss, J. K. Lazo, and C. Trumbo, 2016: The effects of past hurricane experiences on evacuation intentions through risk perception and efficacy beliefs: A mediation analysis. Wea. Climate Soc., 8, 327-344, doi:10.1175/WCAS-D-15-0074.1.

Dixon, G. N., 2015: Negative affect as a mechanism of exemplification effects: An experiment on two-sided risk argument recall and risk perception. Commun. Res., 43, 761-784, doi:10.1177/0093650215579222.

_ B. W. McKeever, A. E. Holton, C. Clarke, and G. Eosco, 2015: The power of a picture: Overcoming scientific misinformation by communication weight-of-evidence information with visual exemplars. J. Commun., 65, 639-659, doi:10.1111/jcom.12159.

Dow, K., and S. Cutter, 1998: Crying wolf: Repeat responses to hurricane evacuation orders. Coastal Manage., 26, 237-252, doi:10.1080/08920759809362356.

Drew, D. G., and T. Grimes, 1987: Audio-visual redundancy and TV news recall. Commun. Res., 14, 452-461, doi:10.1177/ 009365087014004005.

Eilam, B., 2012: Teaching, Learning, and Visual Literacy: The Dual Role of Visual Representation. Cambridge University Press, $322 \mathrm{pp}$.

Eosco, G. M., 2014: Exploring risk and uncertainty perceptions in weather broadcasts using real-time response to measure visual effects. Ph.D. dissertation, Cornell University, 169 pp.

—, J. Steinhardt, C. W. Scherer, and M. Chock, 2012: Visual typologies: Expanding how we think about visualizing risk uncertainty. Extended Abstracts, Society for Risk Analysis Annual Meeting, San Francisco, CA, Society for Risk Analysis, M2-D.3. [Available online at http://birenheide.com/sra/ 2012AM/program/singlesession.php3?sessid=M2-D.]

Evans, J. S. B. T., 2008: Dual-processing accounts of reasoning, judgment, and social cognition. Annu. Rev. Psychol., 59, 255-278, doi:10.1146/annurev.psych.59.103006.093629.

Flynn, J., P. Slovic, and C. K. Mertz, 1994: Gender, race, and perception of environmental health risks. Risk Anal., 14, 1101-1108, doi:10.1111/j.1539-6924.1994.tb00082.x.

Goodman, N., 1969: Languages of Art: An Approach to a Theory of Symbols. Oxford University Press, 277 pp.

Goodwin, C., 1994: Professional vision. Amer. Anthropol., 96, 606633, doi:10.1525/aa.1994.96.3.02a00100.

Grimes, T., 1990: Audio-video correspondence and its role in attention and memory. Educ. Technol. Res. Dev., 38, 15-25, doi:10.1007/BF02298178.

Hart, P. S., 2014: Boomerang effects in risk communication. Effective Risk Communication, J. Arvai and L. Rivers III, Eds., Routledge, 304-318.

— and E. C. Nisbet, 2012: Boomerang effects in science communication: How motivated reasoning and identity cues amplify opinion polarization about climate mitigation policies. Communic. Res., 39, 701-723, doi:10.1177/0093650211416646.

Harvatt, J., J. Petts, and J. Chilvers, 2011: Understanding householder responses to natural hazards: Flooding and sea-level rise comparisons. J. Risk Res., 14, 63-83, doi:10.1080/ 13669877.2010.503935.

Hochberg, J., and V. Brooks, 1962: Pictorial recognition as an unlearned ability: A study of one child's performance. Amer. J. Psychol., 75, 624-628, doi:10.2307/1420286.

Horney, J. A., P. D. M. MacDonald, M. Van Willigen, P. R. Berke, and J. S. Kaufman, 2010: Individual actual or perceived 
property flood risk: Did it predict evacuation from Hurricane Isabel in North Carolina, 2003? Risk Anal., 30, 501-511, doi:10.1111/j.1539-6924.2009.01341.x.

Jackson, S. A., 1992: Message Effects Research: Principles of Design and Analysis. Guilford Press, 184 pp.

Jenni, K., and G. Loewenstein, 1997: Explaining the identifiable victim effect. J. Risk Uncertainty, 14, 235-257, doi:10.1023/ A:1007740225484.

Jung, K., S. Shavitt, M. Viswanathan, and J. M. Hilbe, 2014: Female hurricanes are deadlier than male hurricanes. Proc. Natl. Acad. Sci. USA, 111, 8782-8787, doi:10.1073/pnas.1402786111.

Kahneman, D., 2013: Thinking, Fast and Slow. Farrar, Straus and Giroux, 499 pp.

King, A. J., 2015: Visual messaging and risk communication. The Sage Handbook of Risk Communication, H. Cho, T. Reimer, and K. A. McComas, Eds., Sage, 193-205.

— J. D. Jensen, L. A. Davis, and N. Carcioppolo, 2014: Perceived visual informativeness (PVI): Construct and scale development to assess visual information in printed materials. J. Health Commun., 19, 1099-1115, doi:10.1080/ 10810730.2013.878004.

— , N. Carcioppolo, D. Grossman, K. K. John, and J. D. Jensen, 2015: A randomized test of printed educational materials about melanoma detection: Varying skin self-examination technique and visual image dose. Health Educ. J., 74, 732742, doi:10.1177/0017896914558645.

Kogut, T., and I. Ritov, 2005: The "identified victim" effect: An identified group, or just a single individual? J. Behav. Decis. Making, 18, 157-167, doi:10.1002/bdm.492.

Lazard, A., and L. Atkinson, 2015: Putting environmental infographics center stage: The role of visuals at the Elaboration Likelihood Model's critical point of persuasion. Sci. Commun., 37, 6-33, doi:10.1177/1075547014555997.

Lazo, J. K., A. Bostrom, R. E. Morss, J. L. Demuth, and H. Lazrus, 2015: Factors affecting hurricane evacuation intentions. Risk Anal., 35, 1837-1857, doi:10.1111/risa.12407.

Liberman, N., and Y. Trope, 2008: The psychology of transcending the here and now. Science, 322, 1201-1205, doi:10.1126/ science. 1161958 .

Lindell, M. K., and S. N. Hwang, 2008: Households' perceived personal risk and responses in a multihazard environment. Risk Anal., 28, 539-556, doi:10.1111/ j.1539-6924.2008.01032.x.

_ and R. W. Perry, 2012: The protective action decision model: Theoretical modifications and additional evidence. Risk Anal., 32, 616-632, doi:10.1111/j.1539-6924.2011.01647.x.

Lipkus, I. M., and J. G. Hollands, 1999: The visual communication of risk. J. Natl. Cancer Inst. Monogr., 25, 149-163.

Lundell, H. C., J. Niederdeppe, and C. E. Clarke, 2013: Exploring interpretation of complexity and typicality in narratives and statistical images about the social determinants of health. Health Commun., 28, 486-498, doi:10.1080/ 10410236.2012.699887.

MacEachren, A. M., and J. H. Gantner, 1990: A pattern identification approach to cartographic visualization. Cartographica, 27, 64-81, doi:10.3138/M226-1337-2387-3007.

—, A. Robinson, S. Hopper, S. Gardner, R. Murray, M. Gahegan, and E. Hetzler, 2005: Visualizing geospatial information uncertainty: What we know and what we need to know. Cartogr. Geogr. Inf. Sci., 32, 139-160, doi:10.1559/ 1523040054738936.

—, R. E. Roth, J. O'Brien, B. Li, D. Swingley, and M. Gahegan, 2012: Visual semiotics \& uncertainty visualization: An empirical study. IEEE Trans. Visual Comput. Graphics, 18, 2496-2505, doi:10.1109/TVCG.2012.279.

Maibach, E., C. Roser-Renouf, and A. Leiserowitz, 2008: Communication and marketing as climate change-intervention assets. Amer. J. Prev. Med., 35, 488-500, doi:10.1016/ j.amepre.2008.08.016.

—_, J. Witte, and K. Wilson, 2011: "Climategate" undermined belief in global warming among many American TV meteorologists. Bull. Amer. Meteor. Soc., 92, 31-37, doi:10.1175/2010BAMS3094.1.

McCright, A. M., and R. E. Dunlap, 2011: The politicization of climate change and polarization in the American public's views of global warming, 2001-2010. Sociol. Quart., 52, 155194, doi:10.1111/j.1533-8525.2011.01198.x.

Messaris, P., 1994: Visual Literacy: Image, Mind, and Reality. Westview Press, 224 pp.

_ 1997: Visual Persuasion: The Role of Images in Advertising. SAGE, $320 \mathrm{pp}$.

Meyer, R. J., 2006: Why we underprepare for hazards. On Risk and Disaster: Lessons from Hurricane Katrina, R. Daniels, D. Kettl, and H. Kunreuther, Eds., University of Pennsylvania Press, 153-174.

NHC, 2012: National Hurricane Center's reviews on the use of scales to communicate the storm surge hazard. NOAA/NWS, accessed 1 April 2016. [Available online at http://www.nhc. noaa.gov/news/20120910_pa_surgeScale.pdf.]

Nisbet, M. C., 2009: Communicating climate change: Why frames matter for public engagement. Environment, 51, 12-23, doi:10.3200/ENVT.51.2.12-23.

NOAA, 2010: NOAA National Weather Service to use new hurricane wind scale: Storm surge and flooding prediction dropped in new scale. Accessed 1 April 2016. [Available online at http:// www.noaanews.noaa.gov/stories2010/20100217_hurricane.html.]

_ 2013: Hurricane/Post-Tropical Cyclone Sandy, October 22-29, 2012. U.S. Department of Commerce/NOAA/NWS Service Assessment, 66 pp. [Available online at http://www.weather. gov/media/publications/assessments/Sandy13.pdf.]

O'Neill, S. J., and M. Hulme, 2009: An iconic approach for representing climate change. Global Environ. Change, 19, 402-410, doi:10.1016/j.gloenvcha.2009.07.004.

— , and N. Smith, 2014: Climate change and visual imagery. Wiley Interdiscip. Rev.: Climate Change, 5, 73-87, doi:10.1002/wcc.249.

- M. Boykoff, S. Niemeyer, and S. A. Day, 2013: On the use of imagery for climate change engagement. Global Environ. Change, 23, 413-421, doi:10.1016/j.gloenvcha.2012.11.006.

Paivio, A., 2007: Mind and its Evolution: A Dual Coding Theoretical Approach. Lawrence Erlbaum Associates, 517 pp.

Peacock, W. G., S. D. Brody, and W. Highfield, 2005: Hurricane risk perceptions among Florida's single family homeowners. Landscape Urban Plann., 73, 120-135, doi:10.1016/j.landurbplan.2004.11.004.

Perini, L., 2012: Image interpretation: Bridging the gap from mechanically produced image to representation. Int. Stud. Philos. Sci., 26, 153-170, doi:10.1080/02698595.2012.703478.

Petty, R. E., and J. T. Cacioppo, 1984: The effects of involvement on responses to argument quantity and quality: Central and peripheral routes to persuasion. J. Pers. Soc. Psychol., 46, 69-81, doi:10.1037/0022-3514.46.1.69.

— , and - 1986: The elaboration likelihood model of persuasion. Adv. Exp. Soc. Psychol., 19, 124-205.

,,-- and R. Goldman, 1981: Personal involvement as a determinant of argument-based persuasion. J. Pers. Soc. Psychol., 41, 847-855, doi:10.1037/0022-3514.41.5.847. 
Rodriguez-Estrada, F. C., and L. S. Davis, 2015: Improving visual communication of science through the incorporation of graphic design theories and practices into science communication. Sci. Commun., 37, 140-148, doi:10.1177/ 1075547014562914.

Schuldt, J. P., S. H. Konrath, and N. Schwarz, 2011: "Global warming" or "climate change"?: Whether the planet is warming depends on question wording. Public Opin. Quart., 75, 115-124, doi:10.1093/poq/nfq073.

Severtson, D. J., 2015: Testing map features designed to convey the uncertainty of cancer risk: Insights gained from assessing judgments of information adequacy and communication goals. Sci. Commun., 37, 59-88, doi:10.1177/ 1075547014565908.

Shah, P., and A. Miyake, Eds., 2005: The Cambridge Handbook of Visuospatial Thinking. Cambridge University Press, 561 pp.

Shapiro, M. A., 2002: Generalizability in communication research. Hum. Commun. Res., 28, 491-500, doi:10.1111/ j.1468-2958.2002.tb00819.x.

Sharma, U., and A. Patt, 2012: Disaster warning response: The effects of different types of personal experience. Nat. Hazards, 60, 409-423, doi:10.1007/s11069-011-0023-2.

Shaw, A., S. Sheppard, S. Burch, D. Flanders, A. Wiek, J. Carmichael, J. Robinson, and S. Cohen, 2009: Making local futures tangible-Synthesizing, downscaling, and visualizing climate change scenarios for participatory capacity building. Global Environ. Change, 19, 447-463, doi:10.1016/ j.gloenvcha.2009.04.002.

Sherman-Morris, K., 2013: The public response to hazardous weather events: 25 years of research. Geogr. Compass, 7, 669-685, doi:10.1111/gec3.12076.

Slovic, P., 2007: "If I look at the mass I will never act": Psychic numbing and genocide. Judgment Decis. Making, 2, 79-95.

Small, D. A., G. Loewenstein, and P. Slovic, 2007: Sympathy and callousness: The impact of deliberative thought on donations to identifiable and statistical victims. Organ. Behav. Hum. Decis., 102, 143-153, doi:10.1016/j.obhdp.2006.01.005.

Sontag, S., 1977: On Photography. Macmillan, 208 pp.
Spence, A., W. Poortinga, C. Butler, and N. F. Pidgeon, 2011: Perceptions of climate change and willingness to save energy related to flood experience. Nat. Climate Change, 1, 46-49, doi:10.1038/nclimate1059.

Taylor, H. A., and B. Tversky, 1992: Spatial mental models derived from route and survey information. J. Mem. Lang., 31, 261-292, doi:10.1016/0749-596X(92)90014-O.

Trope, Y., and N. Liberman, 2010: Construal level theory of psychological distance. Psychol. Rev., 117, 440-463, doi:10.1037/a0018963.

Trumbo, C., M. Lueck, H. Marlatt, and L. Peek, 2011: The effect of proximity to Hurricanes Katrina and Rita on subsequent hurricane outlook and optimistic bias. Risk Anal., 31, 19071918, doi:10.1111/j.1539-6924.2011.01633.x.

Trumbo, J., 1999: Visual literacy and science communication. Sci. Commun., 20, 409-425, doi:10.1177/1075547099020004004.

Tversky, A., and D. Kahneman, 1974: Judgment under uncertainty: Heuristics and biases. Science, 185, 1124-1131. [Available online at http://www.jstor.org/stable/1738360.]

Wells, G. L., and P. D. Windschitl, 1999: Stimulus sampling and social psychological experimentation. Pers. Soc. Psychol. Bull., 25, 1115-1125, doi:10.1177/01461672992512005.

Whitmarsh, L., 2008: Are flood victims more concerned about climate change than other people? The role of direct experience in risk perception and behavioral response. J. Risk Res., 11, 351-374, doi:10.1080/13669870701552235.

Wogalter, M. S., Ed., 2006: Handbook of Warnings. Lawrence Erlbaum Associates, $841 \mathrm{pp}$.

Zhao, X., A. Leiserowitz, E. W. Maibach, and C. Roser-Renouf, 2011: Attention to science/environment news positively predicts and attention to political news negatively predicts global warming risk perceptions and policy support. J. Commun., 61, 713-731, doi:10.1111/j.1460-2466.2011.01563.x.

Zillmann, D., 1999: Exemplification theory: Judging the whole by some of its parts. Media Psychol., 1, 69-94, doi:10.1207/ s1532785xmep0101_5.

, 2002: Exemplification theory of media influence. Media Effects: Advances in Theory and Research, J. Bryant and D. Zillmann, Eds., Lawrence Erlbaum Associates, 19-42. 